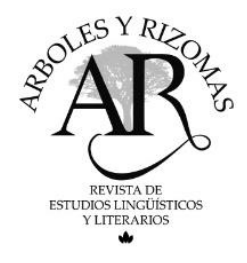

Árboles y Rizomas Vol. II, No 2 (julio-diciembre, 2020): 88-105

Universidad de Santiago de Chile, ISSN 0719-9805

https://doi.org/ 10.35588/ayr.v2i2.4674

\title{
El diario de vida de Claudio Bertoni como campo de prueba de su obra ${ }^{1}$
}

\author{
Claudio Bertoni's diary as testing ground for his work
}

\author{
Mariela K. Jara Rosales ${ }^{2}$
}

\begin{abstract}
Resumen
En toda obra es posible aplicar una lectura autobiográfica y literaria, pero es en el diario íntimo donde esta dicotomía realidad/creación pasa a primer plano, motivo por el que se hace necesario ahondar en este tipo de escritura. En la presente investigación analizaré los cuadernos personales de Claudio Bertoni publicados como libros: Rápido, antes de llorar (2007) y ¿A quién matamos ahora? (2011). Intentaré demostrar que ambos textos corresponden al eje de su obra, como origen y campo de prueba de su creación artística; del estudio de los diarios de vida de escritores podemos no solo extraer datos biográficos, sino también conocer sus sistemas estéticos, sus creencias y sus procesos de escritura. La metodología de investigación consistirá en definir y describir las características propias del diario de vida como género, para luego analizar los diarios del poeta chileno usando tanto ejemplos de textos o poemas que hayan sido publicados a partir de su diario como temáticas frecuentes en sus cuadernos personales, su poesía y su trabajo visual. Para este último aspecto del análisis, me enfocaré en las similitudes entre la práctica del diario íntimo y la fotografía, tomando como materia de estudio sus libros Chilenas (2009), Desnudos (2009) y Desgarraduras (2009).

Palabras clave: Claudio Bertoni, diario íntimo, poesía, fotografía.
\end{abstract}

\begin{abstract}
It is possible to use an autobiographical and literary reading for any work, but in the intimate diary the reality / creation dichotomy comes to the fore, which is why it is necessary to delve into this type of writing. In this article, I analyze two of Claudio Bertoni's intimate diaries published as books: Rápido, antes de llorar (2007) and ¿A quién matamos ahora? (2011). I try to show that both texts are the core of his work, as origin and testing ground of his artistic creation. From the study of writers' diaries, it is possible to not only extract biographical data but also know their aesthetic systems, their beliefs and their writing processes. The research methodology consists in defining and describing the characteristics of the diary as genre, and then analyzing the intimate diaries of the Chilean poet by identifying both examples of texts or poems that have been published from his diaries and frequent themes in his personal notebooks, his poetry and his visual work. For this last aspect of the analysis, I focus on the similarities between the practice of the intimate diary and photography in his books Chilenas (2009), Desnudos (2009) and Desgarraduras (2009).

Key words: Claudio Bertoni, personal diary, poetry, photography.

1 Trabajo derivado de la tesis "El diario de vida de Claudio Bertoni como campo de prueba de su obra", guiada por el académico Felipe Cussen y presentada como requisito para obtener el grado de Magíster en Literatura Latinoamericana y Chilena, Universidad de Santiago de Chile, 2019.

${ }^{2}$ Investigadora independiente: kimberly.jara@gmail.com
\end{abstract}

Recibido: 14.10 .2020

Aceptado: 27.11.2020 


\section{Introducción}

Poeta, diarista, artista visual y columnista de The Clinic, Claudio Bertoni ha producido hasta la fecha una obra extensa y con una diversidad de formatos que incluyen sus diarios - donde mezcla narrativa y diversas técnicas poéticas-, sus libros de poemas, sus libros de citas y comentarios, sus columnas de opinión, su autobiografía Cabro chico (2018) y sus libros de fotografías e instalaciones como Chilenas (2009) o Desgarraduras (2009). Cada una de estas publicaciones gira en torno a un núcleo común: sus diarios de vida.

Los cuadernos personales de Bertoni escritos al modo de "un diario de vida o libro de poesía sui generis" (Bertoni, 2007, p.9) utilizan una forma abierta y desordenada de narrar la realidad para expresar algo que va más allá de la pura referencia a la vida personal. Todos aquellos pasajes escritos en un estilo coloquial, a modo de larga conversación con el lector, buscan transmitir mensajes más profundos sobre la realidad: nos encontramos con la sensibilidad del yo estimulada con lo mínimo de la vida, con la vulgaridad del día a día. Ambos diarios, Rápido, antes de llorar Cuadernos 1976-1978 (publicado en 2007) y ¿A quién matamos ahora? Cuadernos 1972-1973 (Publicado en 2011), se configuran en un aparente desorden donde se mezclan cartas, descripciones de sueños, citas, poemas y narraciones de lo cotidiano.

En el presente trabajo me propongo establecer una relación entre el contenido de sus diarios (ambos volúmenes publicados) y el resto de su obra. La metodología consistirá en identificar ejemplos de textos o poemas que hayan sido publicados a partir de su diario y temáticas frecuentes en sus cuadernos personales, su poesía y su trabajo visual. Para este último aspecto del análisis, me enfocaré en las similitudes existentes entre la práctica del diario íntimo y la fotografía, tomando como materia de estudio sus libros de fotografía Chilenas (2009), Desnudos (2009) y Desgarraduras (2009).

\section{El diario de vida como campo de prueba del escritor}

El diario íntimo como género ha sido reconocido dentro de la teoría literaria hace no más de dos siglos aproximadamente (Morales, 2014, p.16). Por una parte, en Europa el diario íntimo nace a partir de prácticas propias de la Reforma y Contrarreforma, pues existía la costumbre de registrar diariamente los pecados como una forma de examinar y controlar el comportamiento moral de las personas. Posteriormente, este tipo de texto evolucionaría influido por diversos factores sociales y culturales: "independizado de sus orígenes religiosos, y con otras funciones, el diario íntimo se instala de manera estable entre los géneros de la literatura europea moderna a partir del siglo XVIII, sobre todo con el Romanticismo y su giro hacia la subjetividad" (Morales, 2014, p.131). Por otra parte, en nuestro país el nacimiento del diario de vida se encuentra asociado al capitalismo y, por consiguiente, al surgimiento de la sociedad burguesa luego de la independencia de los países hispanoamericanos. Es por ello que en este lado del mundo los primeros diarios íntimos conocidos datan apenas de la segunda mitad del siglo XIX, consolidándose recién como una práctica común durante el siglo XX (Morales, 2014).

Para definir y explicar las características del diario de vida se hace imperioso hablar de su cualidad autobiográfica. Según Philippe Lejeune (1994) la escritura autobiográfica se basa en dos principios fundamentales: el de la identidad, a saber, la identificación del autor con el narrador y personaje principal; y el de veracidad, el cual se refiere a la constante referencia a hechos de la vida real. De este último principio se desprende lo que Lejeune denomina el pacto autobiográfico; es decir, que una autobiografía - o, en el caso de esta investigación, un diario personal-afirme que 
lo dicho en ella es verdadero no significa que lo sea, sino que el autor dice que es la verdad y, por tanto, el lector en una especie de acuerdo tácito decide confiar en él y creerle. En palabras de Lejeune (1994), "el pacto autobiográfico es la afirmación en el texto de esta identidad (narrador y personaje), y nos envía en última instancia al nombre del autor sobre la portada" (p. 64).

Ahora bien, las características propias de un diario de vida según Lejeune (1994) son la forma del lenguaje -narración en prosa-; el tema tratado -vida individual, historia de una personalidad-; la situación del autor-identidad del autor, cuyo nombre reenvía a una persona real y al narrador-; y la posición del narrador -identidad del narrador y del personaje principal-. A estos aspectos del relato autobiográfico que define Lejeune debemos agregar características propias del diario personal como formato de escritura, entre los cuales podemos mencionar la narración de hechos cotidianos a través de la cláusula del calendario -hacer referencia a la fecha diaria-; su carácter fragmentario en el sentido de que su único requisito formal es la escritura por fechas; y, por último, su forma abierta que puede abarcar todo - cartas, citas, narraciones, poemas, etc.- , otorgándole al texto esta aparente desorganización que muchos autores relacionan con el collage o un "libro de bosquejos" (Luque, 2016).

Por otro lado, es relevante aclarar la relación entre el autor real del diario de vida y el narrador o personaje central. Respecto a esto último, Paul de Man (1991) niega completamente la correspondencia entre el autor real de un diario y el yo presente en el texto, pues para él el formato del diario de vida no es más que una gran figura retórica:

¿No será que la ilusión referencial proviene de la estructura de la figura, es decir, que no hay clara y simplemente un referente en absoluto, sino algo similar a una ficción, la cuál, sin embargo, adquiere a su vez cierto grado de productividad referencial? (De Man, 1991, p. 113).

Es decir, la correspondencia entre el yo del diario y la figura real del autor se convierte en un recurso retórico, en una ilusión referencial. De este modo, nos encontramos ante un desdoblamiento del sujeto del diario que al intentar establecer su yo dentro de la escritura, no hace más que distanciarse inevitablemente de él. Por consiguiente, el autor termina en el borde de la literatura y la vida real, siendo su identidad construida por el texto y el lector de un modo enteramente simbólico (Campillo, 1992).

Por otra parte, el crítico y teórico literario George Steiner en su libro Diez (posibles) razones para la tristeza del pensamiento (2007) hace evidente la imposibilidad del ser humano para hacer referencia fiel de su realidad a través del lenguaje. Steiner (2007) señala que estar presente en el mundo y poseer una identidad propia como sujetos se basa enteramente en nuestra capacidad de pensar, pues a través de nuestras ideas y convicciones definimos quiénes somos. Sin embargo, aun cuando el lenguaje da forma a nuestras ideas, nos es imposible compartir nuestra interioridad: "hacer que otro ser humano 'lea' los pensamientos de uno no es más que una figura retórica" (Steiner, 2007, p.27). Al intentar traspasar lo que ocurre dentro de nuestras cabezas solo estamos falsificando o disfrazando lo que sentimos; de este modo, todo intento de poner por escrito la realidad está condenada al fracaso: "la experiencia, cuando tendría que estar desnuda y ser adánica, es filtrada y se ve esencialmente en peligro [...]. Así, no hay en la existencia ningún elemento que no esté debilitado por el pálido tinte del pensamiento" (2007, p. 60). En otras palabras, todo está mediado por nuestra subjetividad, convirtiendo la realidad en un fin inaccesible.

A partir de lo expuesto, y considerando tanto su cualidad autobiográfica como su cualidad ficcional, el diario de vida se define como: 
Aquel texto que, escrito desde el presente y narrado en forma de crónica cotidiana, está protagonizado por un Yo que registra su día a día mediante entradas a veces fechadas y que, además, puede soportar una lectura literaria, en tanto que se construye con los mismos materiales de la ficción (Luque, 2016, p. 297).

De esta manera, el formato del diario de vida se acerca tanto a la novela -narra hechos cotidianos- como a la poesía -expresa la subjetividad de un yo-. En relación a esto último, cabe mencionar que el impulso y necesidad de expresar su vida interior, emociones o sentimientos, son rasgos que comparten tanto el escritor de un diario como un poeta (Luque, 2016).

A partir de sus características particulares -destacándose su estructura abierta-, el diario de vida provee al escritor o artista de un apoyo creativo; es decir, se presenta como un campo de prueba donde no solo se desarrollan las temáticas y problemáticas de sus obras, sino que también es un lugar donde son escritas muchas de sus creaciones (narraciones, poemas, ensayos, etc.) antes de ser editadas y publicadas. Es así como del estudio de los diarios de vida de escritores no solo podemos extraer datos biográficos, sino que también conocemos sus sistemas estéticos, sus creencias, sus opiniones y sus procesos de escritura.

Un caso emblemático es el diario íntimo de Franz Kafka (1883-1924). En el podemos encontrar narraciones de su vida cotidiana, registro de sus sueños y el inicio de 137 narraciones inconclusas (Kafka, 2010), además de asistir al combate librado por el autor en el que se enfrentan la vida y la literatura: "Toda la relación vida-literatura está en juego allí. Aun dejando de lado el motivo del combate, el Diario es tal vez ejemplarmente el lugar en el que dicha relación pasa a primer plano" (Cueto, 2007-2008, p. 2). Así, el diario de vida se configura no solo como el campo de prueba de la obra, sino que también como la tabla de salvación o espacio de desahogo del artista.

Otro caso es el del poeta norteamericano perteneciente a la Generación Beat, Allen Ginsberg (1926-1997), quien fue un asiduo escritor de diarios y cartas en las que relataba sus múltiples viajes por India y Sudamérica. Este registro cotidiano fue materia prima para la creación literaria de Ginsberg, pues buena parte de su obra nace de sus anotaciones personales a las cuales les quebraba los renglones para transformarlas en poemas. Por lo tanto, encontramos en sus diarios la fuente de su creación literaria, ya que estos encarnan la espontaneidad y la honestidad del poeta (Ginsberg, 2018).

Alejandra Pizarnik (1936-1972), poeta y traductora argentina, es otro buen ejemplo, pues en sus diarios íntimos - que suman alrededor de veinte cuadernos, además de hojas sueltas mecanografiadas- también encontramos un lugar de aprendizaje y ensayo, tan importante como sus poemas. Pizarnik se cuestiona constantemente su escritura, siendo su cuadernillo un lugar seguro en el que apoyarse ante la adversidad futura (Pizarnik, 2014). En consecuencia, no es de extrañar que sus páginas también contengan una buena cantidad de poemas de su propia autoría intercalados entre las narraciones cotidianas.

Por otra parte, en Veneno de escorpión azul. Diario de vida y de muerte (escrito en 2006) de Gonzalo Millán (1947-2006), también tenemos un ejemplo donde el diario íntimo presenta parte de la obra del autor; aun cuando en este caso, el diario de vida constituye un espacio de desahogo ante la pronta muerte de Millán. En su diario, el poeta incluye poemas intercalados con narraciones fragmentarias de su estado de salud, narraciones de sueños y reflexiones sobre la vida y la muerte (Millán, 2007).

Se hace necesario también destacar la obra del autor chileno Luís Oyarzún (1920-1972). Su trabajo lo llevó a viajar por varios países del mundo y a escribir extensos diarios de viajes llenos de descripciones, críticas y reflexiones personales (Oyarzún, 2016). Sin embargo, el de Oyarzún es un diario llevado desde su juventud (hacia fines de 1930) y a lo largo de toda su vida, cerrándolo 
solo un día antes de morir. De este diario íntimo es de donde nacen la mayoría de sus obras incluso cuando han sido publicadas como ensayos- entre las que podemos mencionar: Diario de Oriente (1960), Mudanzas del tiempo (1962), Leonardo da Vinci y otros ensayos (1964) y Temas de la cultura chilena (1967). Cabe indicar que en cada una de ellas se encuentra presente el aspecto autobiográfico, inevitable si pensamos en su origen común.

En cuanto a los cuadernos personales de Claudio Bertoni, como en los ejemplos señalados, también se mezclan la vida y la creación poética. Antes de comenzar con el análisis de su obra, se hace necesario ahondar en la edición de ambos diarios íntimos, pues conocer dicho proceso nos ayudará a comprender mejor el vínculo existente entre los diarios de vida y la obra del autor.

La edición de ambos diarios, Rápido, antes de llorar y ¿A quién matamos ahora?, es realizada por Vicente Undurraga - a quien tuve la oportunidad de entrevistar para la presente investigación- a partir de las transcripciones hechas por el mismo Bertoni, quien realiza una primera selección de lo que quiere publicar. Según cuenta Vicente Undurraga, el material que posee Bertoni es demasiado extenso y caótico, pues comienza a escribir desde muy joven y en diferentes soportes materiales: agendas, cuadernos, grabaciones en casetes, papeles sueltos, etc. A partir de esto, se decide en conjunto con el autor - de quién nace la idea de publicar este materialbuscar zonas de interés que pudieran ser publicadas, dejando de lado un abordaje más sistemático y cronológico: "El periodo que recoge el Rápido, antes de llorar, que son al final del 76-78, era uno de los periodos que él estaba más contento con esa escritura" (V. Undurraga, comunicación personal, 26 de agosto de 2019), motivo por el que es el primero en publicarse.

Un alcance importante que hace el editor sobre ambos volúmenes, es el hecho de que se les denomina "cuadernos" y no "diario íntimo". Esta distinción nace a partir de la gran variedad de textos que contienen estos cuadernos donde conviven distintos sistemas de puntuación o formatos y distintas normas de selección o criterios. Al respecto, Vicente Undurraga hace referencia al carácter "abierto" que poseen los distintos cuadernos recopilados en la edición: "hablar más bien de cuadernos porque nos parece que es la palabra que mejor lo recoge [...] que describe una circunstancia muy pedestre muy incluso poco relevante y poco determinante de escritura [y] que por lo tanto todo puede ser" (V. Undurraga, comunicación personal, 26 de agosto de 2019).

A causa de este registro caótico y poco organizado de los originales, la edición de ambos diarios constituye una tarea con un doble propósito: por un lado, mantener el espíritu autobiográfico y natural de la escritura; pero, por otra parte, dicho en palabras del editor "que no fuera una mera transcripción de una letra muerta" (V. Undurraga, comunicación personal, 26 de agosto de 2019). Hacer convivir las distintas líneas que constituyen los cuadernos originales cartas, poemas, narraciones, citas, etc.-, pero equilibrando el contenido, siendo necesario sacar ciertos elementos como, por ejemplo, cartas demasiado extensas o poemas publicados en libros anteriores.

Un aspecto relevante de señalar antes de pasar al análisis, es que estos cuadernos representan para Claudio Bertoni el origen de toda su obra. Como mencionó Vicente Undurraga, parte del contenido presente en los cuadernos originales ya se había publicado. Aun así, es posible rastrear el origen de muchos de sus poemas.

\section{Los cuadernos personales de Bertoni como campo de prueba de su obra literaria}

"Los diarios de Bertoni están en la misma línea que su poesía, son su expresión literaria" (V. Undurraga. comunicación personal, 26 de agosto de 2019), afirma el editor de los diarios, por lo que no es extraño poder rastrear los poemas publicados con anterioridad y que originalmente 
formaban parte de sus cuadernos. Por ejemplo, es posible identificar algunos de estos poemas por las fechas que el autor agrega -ya sea como título o pie de página- y que coinciden con el periodo de tiempo de sus diarios:

\section{UN PERRO}

Salí a caminar antes que oscureciera

estuve casi una hora sentado en la Plaza Pedro de Valdivia

un perro color barquillo se acercó y me lamió la mano

yo le hice cariño y se tendió a mi lado

minutos después lo despertó una sirena de incendio

calculé que se hubiera dormido

me levanté con cautela y me fui

$9 / 72$

(Bertoni, 2014, p.17)

23/ 4/ 2000

Dios mío no me abandones.

Y si no estás ahí...

(Bertoni, 2005, p.192)

¡Mucho menos!

En el primer poema se nos señala en la parte inferior el mes y el año (9/72), periodo correspondiente a la inminente partida de Bertoni a Europa. Posiblemente, este poema fue descartado al momento de editar ¿A quién matamos ahora?, pues forma parte de un poemario anterior: El cansador intrabajable (1973). En el segundo ejemplo encontramos como título del poema la fecha (23/4/2000), aludiendo de forma evidente a la entrada de un diario de vida. Además, en este segundo poema Bertoni desarrolla uno de los temas que recorre gran parte de su obra, que es la existencia o inexistencia de Dios, tema del cual se desprenden la soledad, el miedo y el desamparo del ser humano.

Si bien son recurrentes en sus libros estos ejemplos donde se indica una fecha que alude a sus diarios, también existen algunos poemas que fueron publicados en sus cuadernos personales y en sus poemarios. Por ejemplo, el poema "Adiós" se incluye en Rápido, antes de llorar (2007) y en el libro Piden sangre por las puras (2009), respectivamente:

\section{ADIÓS}

adiós axilas de roja virutilla de B

adiós ojos verdes cinematográficos de $\mathrm{B}$

adiós piececitos de porcelana que se limpiaban uno con el empeine del

otro antes de entrar en la cama, de B

adiós cráneo de Ludwig van Beethoven de B

adiós nalgas de mejillas de orangután de $B$

adiós piel suave y perfumada de $\mathrm{B}$

adiós pequeñas orejas perfectas de $\mathrm{B}$

adiós muslo derecho abollado por un Renault de $\mathrm{B}$

adiós calzoncitos de cuando tenías 12 años que te ponías cuando

hacíamos el amor

adiós muslo incólume izquierdo de B 
Mariela K. Jara Rosales

adiós gritos de amor de $\mathrm{B}$ que hicieron callarse al obrero andaluz que cantaba flamenco mientras pintaba el departamento de al lado adiós París

adiós centro Pompidou que nunca conocí

adiós Saco e bianco de Alberto Burri en el Museo de Arte Moderno de París

adiós puente de las Bellas Artes

adiós pedacito de la torre de Montparnasse visible desde nuestra ventana

$[\ldots]$

(Bertoni, 2007, pp. 92-93)

\section{ADIÓS}

adiós axilas de roja virutilla de $\mathrm{B}$ adiós ojos verdes cinematográficos de $\mathrm{B}$

adiós piececitos de porcelana que se limpiaban uno con el empeine del otro antes de entrar en la cama de B adiós cráneo de Ludwig van Beethoven de B adiós nalgas de mejillas de orangután de B adiós piel suave y perfumada de B adiós pequeñas orejas perfectas de $\mathrm{B}$ adiós muslo derecho abollado por un Renault de B adiós calzoncitos de cuando tenías 12 años que te ponías cuando hacíamos el amor adiós muslo incólume izquierdo de $\mathrm{B}$ adiós reclamos de amor de $\mathrm{B}$ que hicieron callar al obrero andaluz que cantaba flamenco mientras pintaba el departamento de al lado adiós París adiós centro Pompidou que no alcancé a conocer adiós Saco e Bianco de Alberto Burri en el Museo de Arte Moderno de París adiós puente de las Bellas Artes adiós pedacito de la torre de Montparnasse visible desde nuestra ventana<smiles>[AlH]C[AlH]</smiles>

(Bertoni, 2009a, p. 34)

En este ejemplo comparativo, podemos ver dos versiones del mismo poema con diferencias en la configuración de los versos (la sangría o espacio en los versos que no inician con "adiós" en la versión de 2007) y en algunas de las palabras (por ejemplo, "gritos de amor de B" es reemplazado por "reclamos de amor de B"). Esta diferencia en la estructura del poema y en la elección de palabras nos da indicios de una revisión y corrección por parte del poeta, desde el original presente en los diarios al definitivo publicado en el poemario. Probablemente, "Adiós" no fue eliminado en la edición de Rápido antes de llorar (2007) porque no había sido publicado en ese momento. Recién en 2009 se incluiría en Piden sangre por las puras. 
Respecto al contenido del poema, este se centra en la evocación de ciertos recuerdos: la añoranza de París, ciudad en la que Bertoni vivió con B. Ambos objetos líricos (París y B) son mencionados y descritos a lo largo de todo el poema: París, a través de la mención de diversos lugares; y B, a partir de metáforas relacionadas con distintas partes de su cuerpo ("ojos verdes cinematográficos de B"). En el caso de la versión del poema presente en la edición del diario, la anáfora "adiós" (enfatizada a partir del orden de los versos) nos transmite un cierre definitivo a una etapa de su vida. Una renuncia al pasado que en el contexto del diario de vida reconocemos como la decisión final a una compleja disyuntiva que atormenta al poeta: "Escucho cintas con la voz de B y con la voz de M, miro fotografías de B y de París. ¿Qué hacer? Son las 8 y me voy a París, son las 11 y ya no sé" (Bertoni, 2007, p.90).

Otro ejemplo similar es el poema XVI del libro Ni yo (1996), el cual también figura en Rápido, antes de llorar:

\section{XVI}

es una herida

que no se cura:

haber salido

de una.

(Bertoni, 1996, p.70)

Es una herida que no se cura: haber salido de una.

(Bertoni, 2007, p.20)

En este caso, la diferencia entre ambas versiones se limita a la estructura de los versos. Respecto a la temática, esta hace referencia al vínculo o lazo existente entre madre e hijo. Esta atracción y necesidad casi dolorosa que existe entre ambos es uno de los motivos por los que Bertoni decide regresar a Chile luego de vivir por alrededor de cuatro años en Europa (1972-1976). Como muestra de esto, encontramos en sus diarios la siguiente entrada en los primeros días de su regreso: "madre comida techo papel y lápiz / gratis" (Bertoni, 2007: p.18).

La cualidad de sus cuadernos personales como punto de partida de su obra es reconocible también por los temas que trabaja Claudio Bertoni: la vida cotidiana, el erotismo, el desamor, el humor, la hipocondría y la existencia o inexistencia de Dios.

Lo cotidiano es un tópico frecuente en su poesía. Sus libros están llenos de narraciones o descripciones de su vida diaria junto a su familia o amigos. Situaciones simples de la vida convertidas en poemas. Sin embargo, el erotismo y el desamor son probablemente los temas con los cuales más se vincula al poeta chileno; el deseo y el dolor por la pérdida de la amada. Ambos temas están presentes en sus diarios y relacionados -en ese contexto- con las dos mujeres con las cuales mantuvo una relación de pareja por esos años: V. en ¿A quién matamos ahora?; y $\mathrm{M}$ en Rápido, antes de llorar. Como muestra, una de las entradas de su diario:

¿Hace cuánto que no hacíamos lo que hicimos? Que lo hicimos como lo hicimos / Mi antebrazo una escofina que pulveriza tu pecho / Tu boca una cloaca y yo un batracio / Tú el yunque / Ensamblas tu pecho en mi axila como una duna / Banderas de carne azotadas por la pasión. (Bertoni, 2011, p.220)

El ejemplo anterior presenta características propias de la poesía de Bertoni en cuanto al lenguaje, el corte entre versos utilizando / y la abundancia de expresiones retóricas ("Tu boca una cloaca y yo un batracio"; "Banderas de carne azotadas por la pasión"; "Llegando al fondo de tu 
vagina"; "me duermo a tu orilla como un náufrago en la playa"). Así como el deseo y el placer son recurrentes al hablar de relaciones de pareja, el abandono de la amada también es una temática propia de sus libros: "Tú ya no me quieres pero la dedicatoria en la primera hoja de los libros que me regalaste todavía me quiere" (Bertoni, 2007, p.56).

Por otra parte, la hipocondría de Bertoni también representa un tema recurrente en su poesía. El constante miedo a la enfermedad y la inminente muerte lo lleva a examinar cada cambio en su cuerpo, cada mancha en la piel, cada cambio en el color de su orina, cada puntada extraña: "No sé qué voy a decirle ya no tengo una pelotita en el testículo izquierdo ¿tendré que hablar de la inflamación a los ganglios en las ingles en Londres hace un año y medio?" (Bertoni, 2007, p.264). Estos temores presentes en sus cuadernos personales, también se convirtieron en temas recurrentes en sus poemas:

\section{NO HAY PEOR CIEGO... \\ Tienes \\ una pequeña puntada \\ justo ahí \\ donde le dijiste al médico \\ que no la tenías.}

(Bertoni, 2005, p.28)

Este tipo de alusiones a una supuesta enfermedad que podría matarlo es fomentado en parte por el recuerdo del cáncer que mató a su abuelo a quién rememora en las páginas de su diario, temiendo sufrir el mismo final. Es por este historial médico que el poeta examina su cuerpo, el color de su orina o los diversos síntomas, ya sean ficticios o reales, que lo aquejan.

Finalmente, un rasgo propio de la poesía y de los diarios de Bertoni son los objetos dotados de vida y voluntad, como por ejemplo el poema "Tres tacitas de greda" publicado en El cansador intrabajable (II) (1986), donde el hablante lírico se ve sitiado por estos objetos que a través de los versos se nos representan como objetos dotados de vida y voluntad. Esta característica en la escritura de Bertoni se extiende a toda su obra -incluyendo la visual- y en todos sus cuadernos personales: "En el patio frente al durazno hago 21 reverencias. (Es lo que piensa el durazno cuando hago flexiones)" (Bertoni, 2007, p. 231).

En síntesis, sus cuadernos personales pueden ser considerados el origen de su obra, el campo de prueba de la creación. Nos permiten comprender su poesía en mayor profundidad y representan un núcleo dentro de su obra. Dicho en palabras de Vicente Undurraga: "la matriz es el cuaderno es el lugar de la escritura donde todo está un poco más salvaje" (V. Undurraga. comunicación personal, 26 de agosto de 2019).

\section{Relación de sus diarios con su obra visual}

Para el siguiente análisis he tomado como objetos de estudio una muestra menor de los siguientes libros: Chilenas (2009), Desgarraduras (2009) y Desnudos 1973-2008 (2013). Respecto a las temáticas a partir de las cuales estableceré una relación entre sus cuadernos personales y su obra visual, vale mencionar las similitudes entre la escritura diarística y la fotografía; el rol de los objetos como entes activos; la intimidad del sujeto, en cuanto a lo cotidiano y las relaciones de pareja; y, por último, la "mirada indiscreta" o el fotógrafo "cazador" del objeto de deseo.

La fotografía y el diario de vida, que a primera vista pueden parecer distantes entre sí, presentan varias similitudes. En primer lugar, en ambos casos nos encontramos con un sujeto en 
primera persona que registra la realidad a través de su propia subjetividad. Es el sujeto quien filtra, selecciona y presiona el botón para captar y congelar un instante en el tiempo:

Así, la foto aparece, en el sentido fuerte, como una "tajada", una tajada única y singular de espacio-tiempo, literalmente "cortada del natural". Huella sacada, sustraída a una doble continuidad. Pequeño bloque de 'estar-ahí', pequeño sobrecogimiento de aquí-ahora, sustraído a un doble infinito. (Dubois, 2017, p. 43)

Al leer la definición que Philippe Dubois - escritor, periodista, crítico y teórico de cine francés- hace sobre la esencia de la fotografía, no puedo menos que recordar aquellas imágenes captadas en pleno movimiento, como las tomadas por Bertoni en sus paseos por Viña del Mar y Santiago (Figura I y Figura II), donde se evidencia la carencia de pose o de artificio, pues son tomas realizadas a escondidas de sus modelos.

Figura I. Chilenas (2009c)

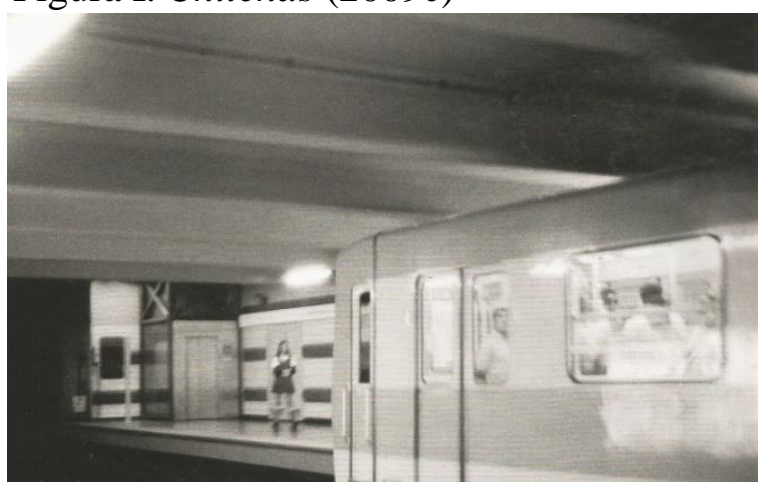
Figura II. Chilenas (2009c)

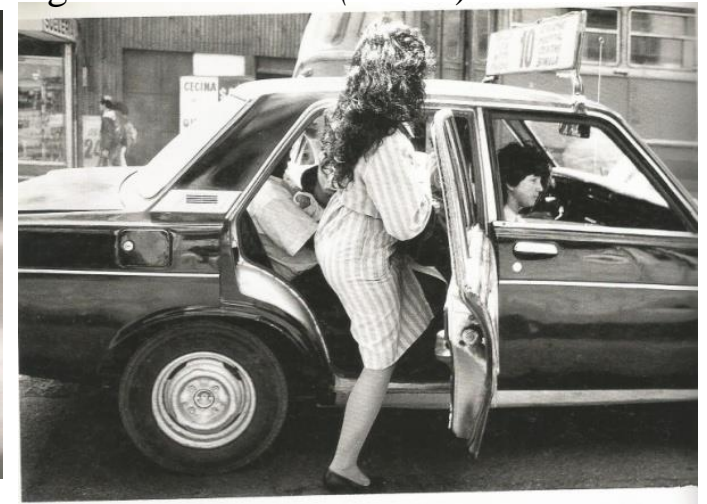

Ambas son imágenes recortadas de la rutina cotidiana y aunque no sea la realidad del sujeto que saca la foto, es el cotidiano que su subjetividad ha seleccionado. De este punto se desprende otra característica afín entre el diario de vida y la fotografía: la imposibilidad de que lo representado corresponda a algo distinto que la ficción o la composición deliberada. Aún cuando la fotografía se encuentra profundamente anclada en la realidad, que nos muestra lugares o hechos que fácilmente podemos reconocer, su descripción del mundo o del sujeto no puede abarcar más que los aspectos exteriores; siempre habrá una perspectiva que el fotógrafo favorecerá en desmedro de otro, dejando un lado oculto, convirtiendo la imagen en una composición o una ficción (Rosenberg, 2017, p. 30). Al igual que sucede con los cuadernos de Bertoni, con sus apuntes, con sus poemas escritos aparentemente "en la emoción del momento" o a través del "apunte rápido", su fotografía nos hace preguntarnos ¿Hasta qué punto muestra la realidad tal como es? ¿Hasta qué punto la toma ha sido natural o preparada? Incluso si las modelos - pensando en el libro Chilenasno han sido informadas como para fingir frente a la cámara, aún quedan múltiples aspectos de selección, enfoque y perspectiva que el fotógrafo encubierto puede manejar para captar la imagen deseada. No quiero que se piense que por esto la obra pierde credibilidad o valor; muy por el contrario, al igual que sucede con el diario de vida, el hecho de que el sujeto que registra y que describe la realidad representa su propia subjetividad le imprime más contenido a su creación.

El rol de los objetos como entes o sujetos activos se encuentra presente en su obra escrita -como por ejemplo en "Tres tacitas de greda"- y en su obra visual. Tomando de referencia el artículo de Gonzalo Montero (2019), el libro Desgarraduras (2009) ofrece variados ejemplos aunque no los únicos- sobre la fuerza que los objetos ejercen sobre el espacio y el sujeto. En esta 
propuesta, el trabajo de Bertoni consistió en tomar al azar algunas de sus diapositivas guardadas durante años, para luego realizarles incisiones con la punta de un alfiler, lo cual nos recuerda inevitablemente el punctum del que habla Roland Barthes, aquello que "[...] sale de la escena como una flecha y viene a punzarme" (Barthes, 2017, p. 58). Atacar o resaltar en las fotografías de su cotidiano aquello que lo hiere es, tal vez, una de las tantas formas en que Bertoni intenta defenderse de la vida.

En Desgarraduras (2009) las fotografías adquieren un nuevo nivel metafórico a partir de las múltiples incisiones efectuadas por la aguja (Fariña, 2009, p.8). Denominado por Adolfo Vera como un fotógrafo del Deseo, pareciera que Bertoni encierra en imágenes todo aquello que rodea su vida (Fariña, 2009) y que a través de la foto busca poseer. Es así como encontramos cuerpos y rostros de mujeres, objetos, paisajes, escenas del interior del hogar e incluso fotografías del mismo Bertoni.

Figura III. Desgarraduras (2009b)

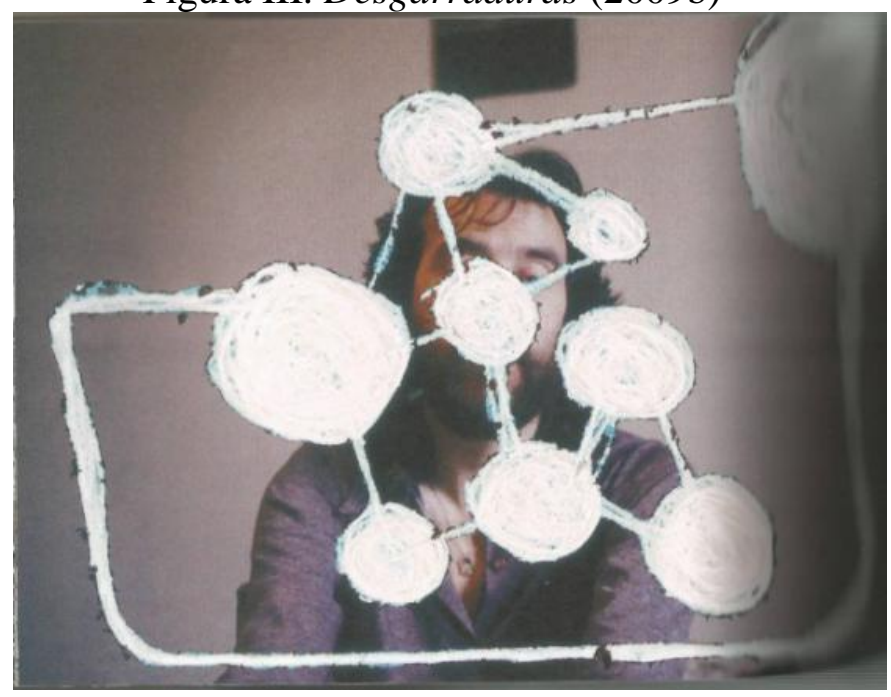

La Figura III nos muestra la representación incompleta del sujeto, pues las desgarraduras en la imagen no nos permiten acceder a lo representado de forma directa y percibir por completo el contenido. Al igual que en el diario de vida, el sujeto se nos muestra segmentado, el yo se representa de forma parcial, dejando la tarea de completar su calidad de sujeto al lector o receptor de la imagen.

Así como en el diario todo lo que rodea al poeta es poetizable, del mismo modo, para el fotógrafo, todo posee potencial artístico. En las fotografías de Bertoni, los objetos cotidianos adquieren el mismo protagonismo en la composición que una persona de carne y hueso. El espacio de su casa es tomado casi por completo por los objetos que se acumulan sin orden ni concierto (Figura IV) desplazando al sujeto en el acto: "si vemos con atención, veremos que a un extremo de la imagen se encuentra el mismo Bertoni acuclillado, asediado por los objetos que lo rodean y que lo han desplazado, hasta casi sacarlo del encuadre" (Montero, 2019, p. 85) 


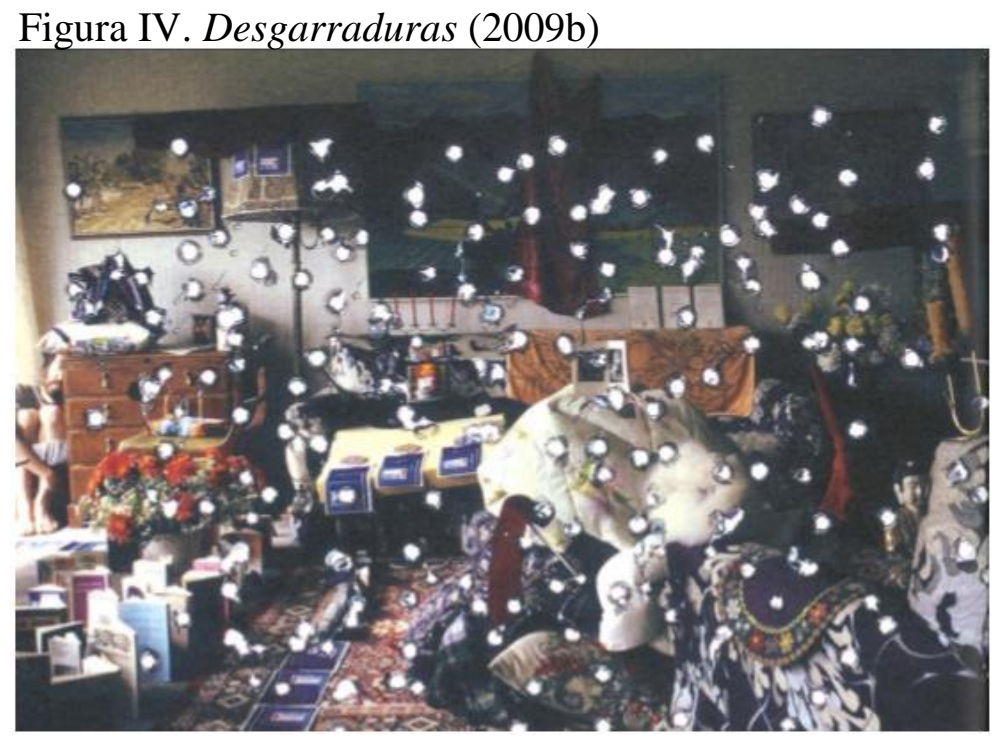

El diario de vida es un tipo de obra que se centra en la vida cotidiana, en la intimidad. El sujeto describe constantemente sus actividades diarias y sus relaciones personales: en el caso particular de Bertoni, nos enteramos de detalles de su vida que van desde asuntos tan triviales como las comidas hasta otros tan íntimos como sus relaciones familiares y amorosas. El poeta chileno se caracteriza precisamente por su falta de pudor al momento de relatar sus intimidades, rasgo que también encontramos en sus fotografías. A continuación, entrego dos ejemplos sobre la forma en que la obra visual del poeta representa su intimidad diaria.

Figura V. Claudio Bertoni Reloj no marques las horas, haz esta noche perpetua 1965-2014. (2014)

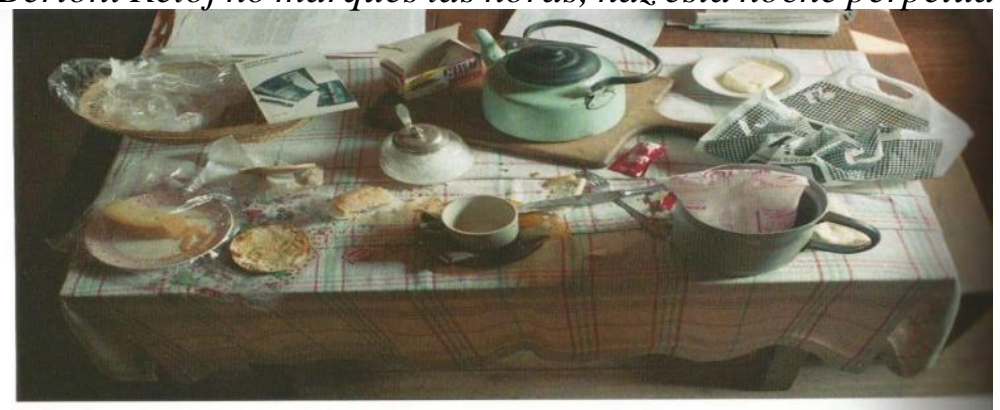

Figura VI Eyaculaciones, $1998^{3}$

${ }^{3}$ Citado en Cussen y Escobar y Florit y Joannon, 2017. 
En primer lugar, vemos una fotografía donde el sujeto nos enseña su propia mesa con las sobras de sus comidas (Figura V), la cual corresponde a una serie de varias imágenes - de la misma mesa y con la misma perspectiva visual-tomadas en distintos días, como si fuera un diario de vida visual de su rutina cotidiana. Y, en segundo lugar, tenemos una fotografía de la serie titulada Eyaculaciones (Figura VI) representando un acto profundamente personal que, al igual que en su diario, Bertoni no duda en exponer y compartir a través de su propuesta visual.

Esta representación de la intimidad cotidiana del hogar también está presente en sus fotografías de Desnudos 1973-2008 (2013); libro que, como dice su título, consiste en una serie de fotografías de desnudos tomadas - la mayoría de ellas- a quienes fueron parejas, amigas o compañeras de Bertoni. Este libro, a pesar de lo que pueda pensarse del título, contiene una gran variedad de estilos en cuanto a las fotografías que podrían dar para un estudio mucho más profundo y completo del que yo puedo realizar en esta sección. Lamentando no poder ahondar en la riqueza de la obra, me limitaré a señalar algunos de los rasgos que estas fotografías tienen en común con el diario de vida.

El primer tema que a cualquiera se le viene inmediatamente a la cabeza es el del erotismo, tan trabajado por el autor chileno. Sin embargo, opto por abordar en primer lugar la forma en que el mundo cotidiano de Bertoni invade muchas de las fotografías de Desnudos, casi como si fuera imposible para el fotógrafo separar a las modelos de la vida cotidiana. Cabe señalar que el mismo Bertoni ha contado en entrevistas que estas fotografías fueron tomadas casi como parte de la rutina diaria, sin preparación previa, sino que obedeciendo a un impulso del momento.

Figura VII. Desnudos 1973-2008 (2013)

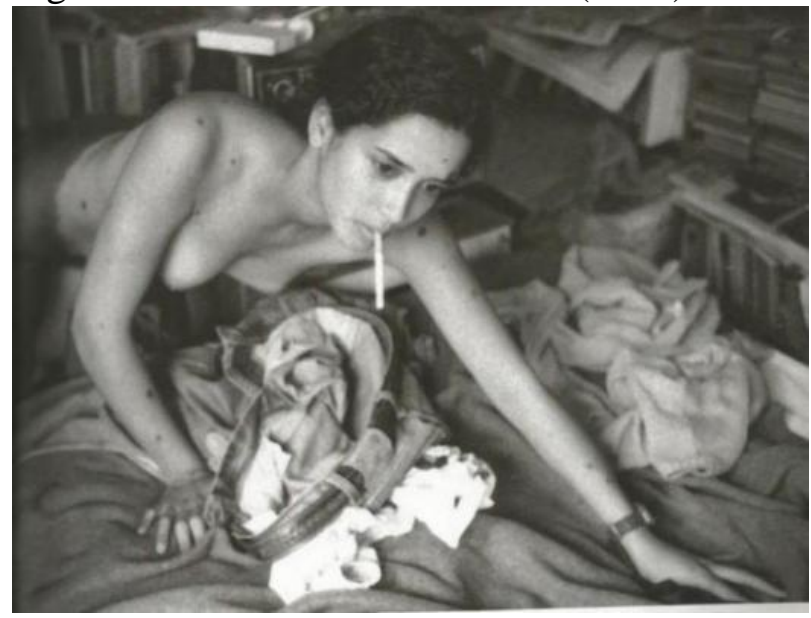

Figura VIII. Desnudos 1973-2008 (2013)

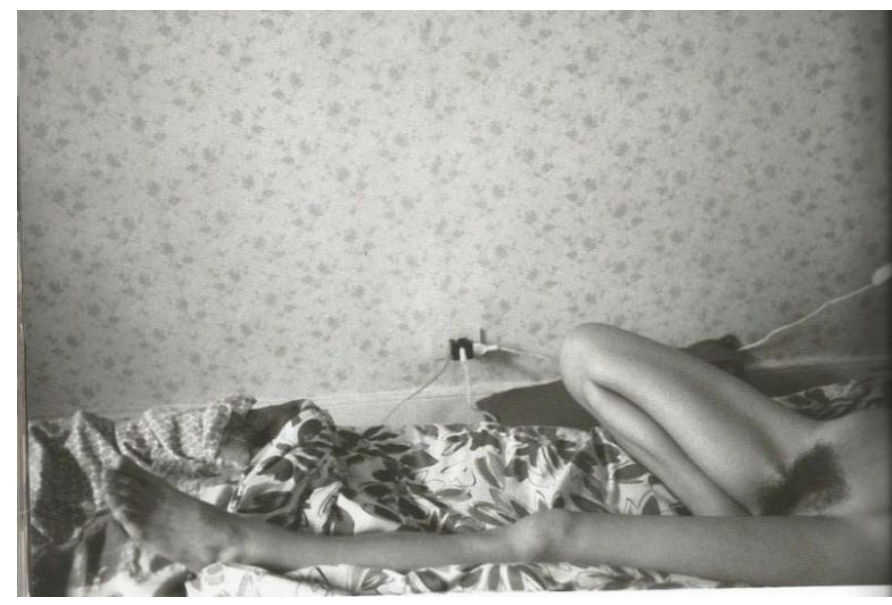

En las Figuras VII y VIII, este rasgo salta a la vista a través de la interacción de las modelos con objetos propios del hogar como la cama y la ropa amontonada. En la primera foto la modelo tiene un cigarro en la boca y parece haber sido capturada por la cámara en medio de una acción completamente natural y cotidiana. En la Figura VIII en la que el desnudo se centra en la parte inferior del cuerpo de la mujer, el enchufe al centro de la imagen capta inevitablemente la atención del espectador. Pareciera que el fotógrafo no se hubiera esforzado en buscar un escenario más estético para su obra; sin embargo, conociendo el estilo de Bertoni -tanto de sus diarios como de sus poemas- es fácil comprender que aquellos elementos no invaden irrespetuosamente los cuadros de la fotografía, sino que han sido previstos y colocados ahí por el artista. 
Respecto al erotismo, al igual que en sus diarios y en sus poemas, Bertoni lo trabaja en Desnudos 1973-2008, agregando en las primeras páginas del libro, como preámbulo a la exposición de sus fotografías, una sugerente intervención de una cita de Paul Valéry:

"Nada es más profundo que la piel" (Paul Valéry)

"Nada es más profundo que la piel de una mujer" (Claudio Bertoni)

(Bertoni, 2013, p.9)

En sus orígenes, el desnudo femenino tendía a ser espiritual y limpio, por lo que omitían el vello del pubis de la mujer, disimulado por sus manos y otros elementos decorativos que contribuían a incrementar la imagen natural y pura de la modelo (Gómez y Parejo, 2004, p. 174). Es a partir de obras de artistas como Courbet, Rodin y Degas - por mencionar unos pocos- que el desnudo femenino comienza a impregnarse de carnalidad sexual: es precisamente la exposición del vello púbico uno de los elementos que producen este cambio en la representación (Gómez y Parejo, 2004). Es así como se dota a la mujer de sexualidad, presentando cuerpos fragmentados, donde la cabeza de la modelo es omitida para otorgar un anonimato - o quizás una universalidada la sexualidad: "hay una enorme frecuencia en la que el cuerpo femenino desnudo es fragmentado y el rostro omitido o tapado" (Gómez y Parejo, p.180).

Figura IX. Desnudos 1973-2008 (2013)

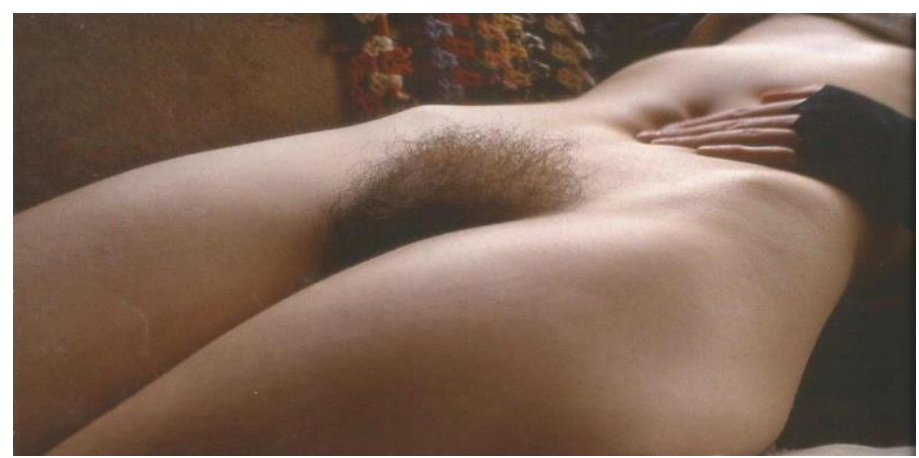

La Figura IX es un buen ejemplo de esta fragmentariedad donde el pubis femenino es el centro de la fotografía, omitiendo prácticamente todo el resto del cuerpo. Resulta al menos llamativo que en la fotografía la mano de la modelo posada sobre su vientre sea la única parte del cuerpo que lleva puesta una prenda, como si con ello se buscara resaltar aún más su desnudez.

Al hablar de fotografías, Roland Barthes (2017) las describía como pertenecientes a una "[...] clase de objetos laminares de los que no podemos separar dos láminas sin destruirlos: el cristal y el paisaje, y por qué no: el Bien y el Mal, el deseo y su objeto: dualidades que podemos concebir, pero no percibir" (p.31). Si pensamos en Desnudos 1973-2008 (2013) y en Chilenas (2009c) estas dos partes laminares de la fotografía bien podrían ser el deseo y su objeto o, como Rita Ferrer señala en el prólogo de Chilenas,

tampoco parecen rebuscadas las asociaciones entre los rituales de la caza y los del erotismo y los enredos que ambos tienen con la muerte que aquí se conjuran en el acto fotográfico: en los instantes irremediablemente muertos en los cuales las imágenes de estas mujeres están congeladas (Ferrer, 2009, p.6). 
Así, en Chilenas el erotismo continúa presente a través de estas fotografías tomadas a mujeres desconocidas en las calles de Viña del Mar y Santiago. Siempre a hurtadillas, desde la distancia, protegido por un pilar o al interior de un microbus (Figura $\mathrm{X}$ ).

Figura X. 3.4.2. Chilenas (2009c)

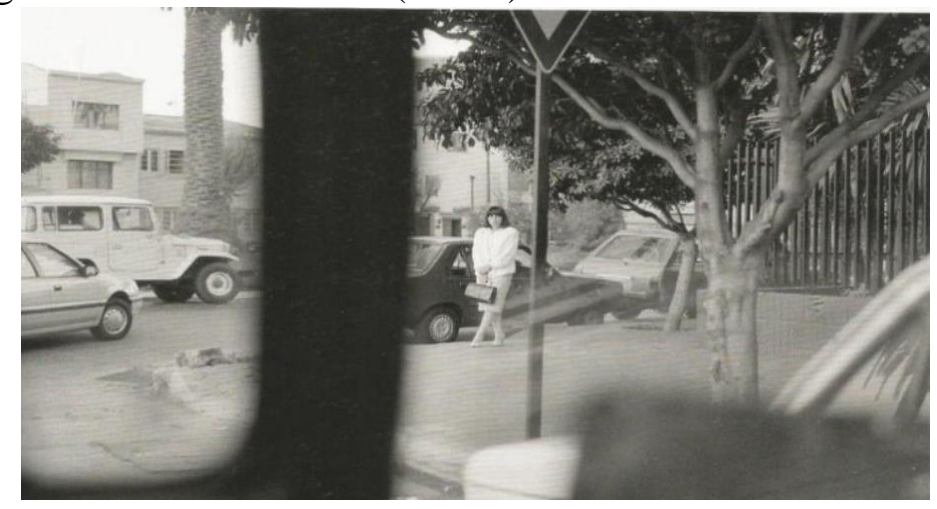

Estas fotografías recuerdan aquellos fragmentos de su diario donde describe a las mujeres con quienes se cruza en la calle o en el microbus y a las cuales también dedica muchos de sus poemas:

[...] cuando se bajó en el mismo paradero que nosotros vi que era bajita y llevaba unos zapatos de terraplén muy altos y me dolió profundamente ver cómo caminaba yo había imaginado que tenía 15 o 16 años aunque M dijo después que ella pensaba que tenía 20 y debe haber tenido razón por la forma en que caminaba con las puntas de los pies más o menos separadas y balanceando cadenciosa su anatomía de un lado a otro como si fuera una enorme madonna [...] (Bertoni, 2007, p.131).

COMPAÑERA DE ASIENTO EN EL BUS DE SANTIAGO A VIÑA no alcanzamos

a tocarnos los brazos

pero nuestros pelitos

-como pestañas-

se tocaron

(Bertoni, 2018, p.47).

En síntesis, a partir de la revisión de las mismas temáticas identificadas en los cuadernos personales de Claudio Bertoni me ha sido posible realizar un análisis de una pequeña muestra de su obra visual. Sobra insistir en el hecho de que esta parte de su obra merece una investigación propia donde se le dé el espacio que realmente merece. Sin embargo, esta breve revisión ha servido para reafirmar la conexión que los diarios de vida de Bertoni tienen con el resto de su creación artística. 


\section{Conclusión}

Resulta necesario destacar el objeto de estudio que representa un diario de vida. En toda obra es posible aplicar una lectura autobiográfica y literaria, sin embargo, es en el diario íntimo donde esta dicotomía realidad/creación pasa a primer plano. A través del análisis de un diario de vida es posible asistir al campo de prueba del escritor y conocer las ideas y experiencias que han influido en su creación y crecimiento como artista. No solo en Claudio Bertoni es posible rastrear el origen de sus poemas y sus obras inconclusas o descartadas, sino que también en Franz Kafka, Alejandra Pizarnik, Allen Ginsberg, entre otros. El diario de vida nos entrega datos de la biografía del autor, eventos y hechos que ocurrieron en un tiempo determinado y que es posible comprobar. Sin embargo, como señala Lejeune (1994), "esta exactitud no tiene importancia capital" (p.77), pues es la función artística la que realmente importa.

A partir de este análisis de la obra de Bertoni cabe preguntarse ¿de qué forma el contexto en que se publica un poema -aislado en un libro de poemas o inmerso en las entradas de un diario íntimo- influye en la recepción que el lector tiene del mismo? El diario íntimo nos muestra el poema en un contexto amplio, al pasar páginas no solo avanzamos en la lectura, sino que avanzamos en el tiempo junto con el sujeto que escribe. Aun cuando sus diarios de vida publicados han pasado por un proceso de selección y edición, queda claro a partir de esta investigación que entregan un contexto enriquecedor para abordar su poesía. No es lo mismo leer un poema de Bertoni aislado en un libro de poemas que encontrarlo en medio de las entradas de su diario, inmerso en un continuo, siendo parte de una narración, de acontecimientos que podemos identificar y relacionar a la escritura.

Si bien los cuadernos personales de Bertoni son el origen de su poesía, es un error pensar que esta forma de escribir es del todo natural. De igual modo, si relacionamos su obra visual con las ideas en sus cuadernos personales, encontramos este mismo "estilo descuidado". Sus fotografías tomadas de forma "improvisada" a las chilenas en las calles de Viña del Mar y de Santiago son en realidad el resultado de una composición previa, una selección hecha por el autor antes del clic que captura la imagen. Esto se evidencia desde el momento en que Bertoni decide intencionalmente recorrer las calles con el propósito de fotografiar mujeres. Lo mismo ocurre con las fotografías de desnudos tomadas al interior de su casa, donde pareciera que la intimidad de su cotidiano se interpone insolentemente en el encuadre, mostrando junto a sus modelos los restos de comida del día, la cama sin hacer, los zapatos regados por el suelo o los enchufes en las paredes. Tanto sus poemas como su obra visual nos presentan el estilo cotidiano y "natural" de sus diarios, así como también sus mismas temáticas.

En síntesis, la presente investigación ha contribuido a reforzar las características de un formato tan escurridizo como es el diario íntimo; reafirmando la importancia que posee no solo respecto a las referencias autobiográficas que puede aportar sobre un determinado autor, sino que también en relación al proceso creativo del artista. Claudio Bertoni es uno de los tantos referentes que, a través de las narraciones cotidianas, la poesía, los desvaríos amorosos, la contemplación de la naturaleza y la lectura reflexiva, nos entrega un complejo y valioso material de estudio: el diario de vida. 
Mariela K. Jara Rosales

\section{Referencias}

Barthes, R. (2017). La cámara lúcida nota sobre la fotografía. Provincia de Buenos Aires: Editorial Paidós Ibérica, S. A.

Bertoni, C. (1986). El cansador intrabajable (II). Santiago de Chile: Las Ediciones del Ornitorrinco.

--------- (1996). Ni yo. Santiago de Chile: Editorial Cuarto Propio (2005). Harakiri. Santiago de Chile: Editorial Cuarto Propio.

(2009 a). Piden sangre por las puras. Santiago de Chile: Editorial Cuarto

Propio.

(2009 b). Desgarraduras. Santiago de Chile: Quilombo Ediciones.

(2009 c). Chilenas. Chile: Ocho Libros Editores.

-- (2011). ¿A quién matamos ahora?, Santiago: Ediciones Universidad Diego

Portales.

-- (2007). Rápido, antes de llorar, Santiago: Ediciones Universidad Diego

Portales.

----------- (2013). Desnudos 1973-2008. Santiago: Ocho Libros Editores.

(2014). Antología (1973-2014). Santiago de Chile: Lumen.

(2018). The price of love. Santiago de Chile: Pequeño Dios Editores.

Campillo, A. (1992). El autor, la ficción, la verdad. Daimon Revista Internacional

De Filosofía, 5, pp.25-46. Recuperado de:

https://revistas.um.es/daimon/article/view/12311

Cueto, S. (2007-2008). Kafka y el arte diario. Centro de Estudios de Teoría y

Crítica Literaria, BOLETIN/13-14, pp. 1-12. Recuperado de:

https://www.yumpu.com/es/document/read/37760871/kafka-y-el-arte-diario-celargorg

Cussen, F., Escobar, D., Florit, A. y Joannon, C. (2017). Una conversación con Claudio Bertoni. Santiago de Chile: Overol.

De Man, P. (1991). La autobiografía como des-figuración. Anthropos: La autobiografía y sus problemas teóricos. Estudios e investigación documental, 29, pp. 13-118. Recuperado de:

https://ayciiunr.files.wordpress.com/2019/08/de-man-p-la-autobiografc3ada-como-desfiguracic3b3n.pdf

Díaz, G. (Ed). (2014). Claudio Bertoni Reloj no marques las horas, haz esta noche perpetua 1965 2014. Santiago de Chile: Ediciones de la cortina de humo.

Dubois, P. (2017). El golpe del corte. En: G. Indij y A. Silva (Ed.) CLIC! Fotografía y Estética (pp. 42-43). Buenos Aires, Argentina: la marca editorial.

Fariña, S. (2009). Ojo y tacto. En: C. Bertoni (2009). Desgarraduras (pp.8-11). Santiago de Chile: Quilombo Ediciones.

Ferrer, R. (2009). El deseo nos arroja fuera de nosotros. En: C. Bertoni (2009). Chilenas (pp. 5-12). Chile: Ocho Libros Editores.

Ginsberg, A. (2018). Allen Ginsberg. Ginsberg Esencial Poemas Canciones Ensayos Diarios Correspondencia Entrevistas Fotografías. Barcelona: Anagrama Compendium.

Gómez, A. y Parejo, N. (2004). La fotografía del pubis natural al pubis rasurado. Variaciones sobre una misma forma. En: Terceras Jornadas: II. Imagen y cultura. Universidad de Málaga. Recuperado de: https://e-archivo.uc3m.es/bitstream/handle/10016/9008/fotografia_gomez_IC_2005.pdf

Jara, M. (2019). El diario de vida de Claudio Bertoni como campo de prueba de su obra (Tesis de Magíster). Universidad de Santiago de Chile, Chile. 
Kafka, F. (2010). Kafka en primera persona. Selección de los diarios de vida de Franz Kafka. Santiago de Chile: LOM Ediciones.

Lejeune, P. (1994). El pacto autobiográfico y otros estudios. Madrid: Megazul Endymion.

Luque, Á. (2016). El diario personal en la literatura: Teoría del diario literario.

Castilla. Estudios de Literatura, Vol. 7, pp. 273-306. Recuperado de:

https://www.researchgate.net/publication/316086880

Millán, G. (2007). Veneno de escorpión diario de vida y de muerte. Santiago de Chile: Ediciones Universidad Diego Portales.

Montero, G. (2019). "Como encender la luz sobre una cosa sin ensuciarla”. La poética de los objetos de Claudio Bertoni. Cincinnati Romance Review, 46, pp. 72-88.

Morales, L. (2014). El diario íntimo en Chile. Chile: RIL editores.

Oyarzún, L. (2016). Diario de Oriente Unión Soviética, China e India. Valdivia, Chile: Editorial Universitaria.

Pizarnik, A. (2014). Diarios. Buenos Aires: Editorial Lumen, S.A.

Rosenberg, H. (2017). ¡Bogart ha muerto!. En: G. Indij y A. Silva (Ed.), CLIC! Fotografía y Estética (pp. 29-30). Buenos Aires: La marca editorial.

Steiner, G. (2007). Diez (posibles) razones para la tristeza del pensamiento. México: Centzontle Siruela. 